Pavel Zakharchenko, Doctor of Sciences (Economic), Professor ORCID: 000000015025797X, ResearcherID: E76982019

Ganna Kostenko, $\mathrm{PhD}$ in Economics, Associate Professor ORCID: 0000-0002-8702-9628

Tatyana Kungurtseva-Mashchenko, Postgraduate student Berdyansk State Pedagogical University, Berdyansk, Ukraine ORCID: 0000000302219543, ResearcherID: E-78002019

\title{
STRATEGIC SYSTEM EFFECTS IN RESORT AND TOURIST SPHERES
}

In modern world economy the resort recreations are one of the most highprofitable spheres of managing. Ukraine owns the powerful resort and tourist potential, which effective development can bring a real economic benefit. The market environment needs are in the form of demand and ways to meet them mediated by the market in the form of structural shifts. They are important for forecasting of behavior of the market of resort and tourist products.

One of the results of economic transformation in the resort economy is a transition to a new development strategy that is the transition from a seller's market to a buyer's market. It, in turn, generates numerous system transformational effects to which number, except transformational crisis, follow to carry and transformational structural shifts. Thus, it is possible to speak about difficult system of transformational effects among which there are as effects, which specifics consist only in quantitative differences of transformational economy from market, and effects, which provide existence of qualitative differences between them. In research, set of indicators, which allow analysing structural shifts in resort-recreation economy upon transition to new strategy of development, is constructed. The structure of system is considered, as set of proportions between elements. The movement of all system is described by the reduced indexes of volumes, and the relative movement of production of resort-recreation products in system - is described by indicators of structural shifts. Expected calculations are executed and scenarios developments of Priazovye resort-recreation complex are gained.

Key words: resort and tourist sphere, economic transformations, strategic system effects, structural shifts, set of indicators. 
Relevance of the research topic. In modern world economy resort-recreation and tourist activity is one of highly profitable spheres and also one of what most dynamically develops. For many countries, this is not only a constantly growing source of financial revenue, but also a source of infrastructure development for territories and the creation of additional jobs by attracting millions of tourists [Campbell, 2018; Ravenscroft, 2019]. Ukraine has a powerful resort-recreation and tourist potential, the effective use of which can bring real economic benefits. Therefore, in the process of market transformation of the economy, the resortrecreation and tourist spheres must occupy one of the leading positions in the structure of the economic complex [Humeniuk, 2019].

Formulation of the problem. The economic transformations of the resort and tourist economy are large-scale and profound transformations of a systemic nature. They have their own patterns and effects, the detection of which not only assess their current state, but also predict trends. Transformation processes are reflected in structural shifts in both consumption and production of resort and tourist products. Thus, there is a need to substantiate the content of strategic systemic effects in the resort-recreation and tourism economy, explaining their role in the structural restructuring of the national economic system and the development of the resortrecreation and tourism sphere on their basis.

Analysis of recent research and publications. Significant scientific contribution to the formation of the theory of strategic systemic effects in the study of mechanisms of transformation of economic structures, structural crises was made by representatives of different schools and areas of economic thought. The theoretical findings of J. Schumpeter, P. Samuelson, J. Van Dain, D. Freeman, J. Forrester, M. Porat, and R. Reich have become the starting points for further research in the field of structural shifts, contributing to a deeper understanding of economic transformations, in particular in the resort-recreation and tourism spheres [Barro, 2016]. However, the problems of forming a structural contour during the transformation of the national economy remain debatable.

Setting objectives. The purpose of the research is to analyze and predict transformational structural changes in the resort-recreation and tourism spheres in the transition to a new development strategy. It provides for the predominant provision of resort-recreation services integrated with the leisure and tourism industries.

Presenting main material. The research of structural changes in the resort and tourist spheres is based on a research paradigm, which is to interpret the phenomenon of economic transformation as a transformation of the multidimensional structure of the economic system, which adequately reflects the changes in its state. The transformation of the structure of the economic system is accompanied by the appearance of additional strategic system effects. According to the accepted goal of research, strategic systemic effects will mean the effects caused by changes in the principles of functioning of the resort and tourist system on the basis of transformations of its structure, which lead to additional opportunities to increase its efficiency. 
One of the problematic issues is the ability to evaluate the effects of various structural interactions in the process of transformation of the resort and tourist spheres. Referring to existing economic theories [Flaschel, 2017; Humeniuk, 2018], we can conclude that there is no universal criterion for evaluating such effects. The way out is to evaluate the strategic systemic effects of interactions of structural variables by identifying objective relationships between them. To do this, it is legitimate, using the methodology of general systems theory, to divide all structural variables that reflect the process of systemic economic transformation into «input» and «output». The first are the variables that appear from the perspective of the researcher as the root causes of structural changes in the resort and tourist spheres, the second - variables that express the consequences of these transformations.

Effects of interaction of output and input transformational variables are always shown in change of resource releases and resource expenses by various sectors of economy and, eventually, the aggregated indicators within all national economic system. Thereby, researches of strategic system effects it is real on the basis of comparison of results and expenses in their resource measurement on all chains of structural interactions, besides taking into account target indicators of development of all economic system [William, 2017].

One of strategic system effects that is shown as result of system economic transformation in resort and tourist spheres, is effect of the main structural shifts technological, resource and organizationally behavioural - in organic interrelations with each other. It should be noted that structural the aspect of development is shown both with mediation of proliferation, and through certain high-quality changes in economy. According to us, the concept of shifts - most reflects the nature of transformational processes, which happen in resort and tourist structures. According to research objectives, under structural shifts we will understand significant changes internal creation of resort-recreation and tourist systems, interrelations between its elements, laws of these interrelations that lead to change of the main system qualities.

Content of structural shifts is change of interstructural and intersystem communications and also the main characteristics (system qualities) of such systems. Thus, the structural shift is a process qualitative change of interrelations between the comparable elements of a system caused uneven by dynamics a ratio of their quantitative characteristics, process of fundamental proportions adaptation to endogenous and exogenous changes of resort-recreation and tourist systems conditions.

We concretize a concept structural shift in resort-recreation and tourist spheres. The matter is that shifts in such structure is the cornerstone of anything shifts in the system of interests both economic entity or their groups, and the certain individual, and shifts appear in the form of macro - meso - and microarray respectively. Economic interests represent incentive motives of actions of consumers and are realized in the form of resort-recreation and tourist needs. They prove as the driving 
force of actions of individuals. The different interests and needs of members of society are internally connected among themselves and represent one complete system. Then, the elementary unit of any structural shift in the economy is micro-displacement, that is, the shift in the economic interests and needs of the individual. At this level, there is a formation and pleasure more than $40 \%$ of interests and requirements. Thus, the foundation of structural shifts in more difficult economic sets is laid. Therefore, shifts in structure of resort-recreation and tourist needs of individuals determine shifts in structure of the resort-recreation and tourist enterprises and complexes, which in turn mediate shifts in structure of the branches of national economy. What finally brings to shifts in structure of the economic «centers of force» at the national and world levels?

Thus, as the main reason for structural shifts in resort-recreation and tourist economy development of a system of social needs acts. Their changes cover structures of solvent demand of economic agents that, interacting with the offer, causes these or those changes in structure of placement of resources that is characterized by certain structural shifts in economy. Structural shifts are preceded by gradual quantitative savings of structural changes, which turn into structural shifts, and can happen in a situation when there is a transformation, but there is no development. Structural shifts have the inertial nature and proceed gradually, step by step, with different intensity and synchronism [Brownrigg, 2017].

Let's construct a set of indicators, which allow analyzing structural shifts in resort-recreation economy. Let $q_{j t}>0$ - the production volume of a resort-recreation product $j$, period $t$ in the natural form, $t=\overline{T_{1}, T_{2}}, T_{1}$ and $T_{2}$ - the beginning and end of the time interval under consideration, $j=\overline{1, n}, n-$ the number of resort-recreation products produced. Such products in the studied period are on sale at the fixed prices, $p_{j}^{\prime}>0, j=\overline{1, n}$. Then the totality $u_{j t}=q_{j t} p_{j}^{\prime}>0, j=\overline{1, n}$ the cost of production $q_{j t}$ in the prices $p_{j}^{\prime}$ denote $v_{t}$ and call the vector of costs for the period $t$.

Vectors of costs for the different periods can differ both in length and the direction. Comparison of lengths of vectors of costs allows to receive summary indexes of volumes, and comparison of their directions - summary indexes of structural shifts. According to such approach the structure of a resort-recreation system is considered as set of proportions between elements. The movement of all system is described by summary indexes of volumes, and relative the movement of the production of resort-recreation products in a system - is described by indicators of structural shifts. The summary economic index does not reflect uniformity or unevenness of economic growth, indicators of structural shifts allow to measure degree of unevenness of economic dynamics.

In economic literature a significant amount of various summary indicators of structural shifts is offered. For our research we will use the following indicators: 
- chain index of production volumes $i_{t}=\left\|v_{t}\right\| /\left\|v_{t-1}\right\|$, which shows the ratio of the lengths of the vectors and gives a summary estimate of the change in the production of resort-recreation products over time from $t-1$ to $t$;

- chain index of structural shifts $d_{t}=\left\|\frac{v_{t}}{\left\|v_{t}\right\|}-\frac{v_{t-1}}{\left\|v_{t-1}\right\|}\right\|$, which shows the distance between the directions of the cost vectors for the current period $t$ and the previous one, and allows us to judge the structural changes. A chain index of structural shifts, based on the comparison of adjacent periods, giving a quantitative assessment of structural shifts at a single step in time, allows solving the problem of analyzing the intensity of structural shifts in the resort-recreation economy. That is, to determine in which of the successive intervals the structure of the population has undergone a more significant transformation, and in which - less. Than bigger $d_{t}$, the more intensively there are structural shifts and vice versa;

- basic index of structural shifts $D_{t_{1}, t_{2}}=\left\|\frac{v_{t_{2}}}{\left\|v_{t_{2}}\right\|}-\frac{v_{t_{1}}}{\left\|v_{t_{1}}\right\| \|}\right\|$, which shows distance between the directions of vectors of costs for two any periods and allows to judge about the structural shifts, which happened for appropriate time.

Thus, summary indicators of structural shifts $d_{t}$ and $D_{t_{1}, t_{2}}$ can be also presented and as distances between the directions of vectors of costs during the comparable periods and as relative measures of a variation of individual indexes of the production of resort-recreation products. The basic index of structural shifts based on comparison of any periods, giving a quantitative assessment of structural shifts for corresponding time, allows solving a problem of the analysis of gradualness of structural shifts. That is, to determine to what extent structural shifts are based on a tendency, and to what extent they are only a result of irregular fluctuations. The more $D_{t_{1}, t_{2}}$, the more the structure of production changed, and vice versa. At the same time, it should be noted that indexes of structural shifts $d_{t}$ and $D_{t_{1}, t_{2}}$, allowing analyzing intensity and progressiveness of such shifts, do not allow solving a problem of the analysis of orientation of structural shifts. That is, they do not allow determining whether the structure of the recreation-recreation system has improved, whether it has deteriorated or remained unchanged.

For the purpose of the solution of the specified problem, we will use the indicator of quality of structural shifts in resort-recreation economy. We will define the index of quality of structure in a look $G_{t}=\sum_{j} \alpha_{j} q_{j t} p_{j}^{\prime} / \sum_{j} q_{j t} p_{j}^{\prime}$. The value $G_{t}$ shows flowing quality of structure of production of a resort-recreation product according to the entered criterion. Growth $G_{t}$ over time and as a result of transformations corresponds to an improvement in the quality of the structure, a decrease - deterioration. 
Based on the data provided in sources [«Materials of economic activity», 2018] we will construct the specified indexes for resort-recreation economy and we will carry out their analysis. The dynamics of the national resort-recreation economy of the period $\left(T_{1}=2000-T_{2}=2020\right)$ in question has a clear character of the transition process. Initially, there was a tendency of a slow recession with periods of small growth, and then there was a tendency to accelerate the recession with the transformation into a transformational crisis (Fig. 1). At the lower point of the recession (2014) the intensity of production of the resort-recreation product is only $37 \%$ of the level of 2000 , that is the resort activity decreased by 2.6 onces. Such scale transformational crisis is caused by a number of the reasons. One of the system-wide reasons is that than the system is more difficult, especially it will undergo deep crisis at transformations.

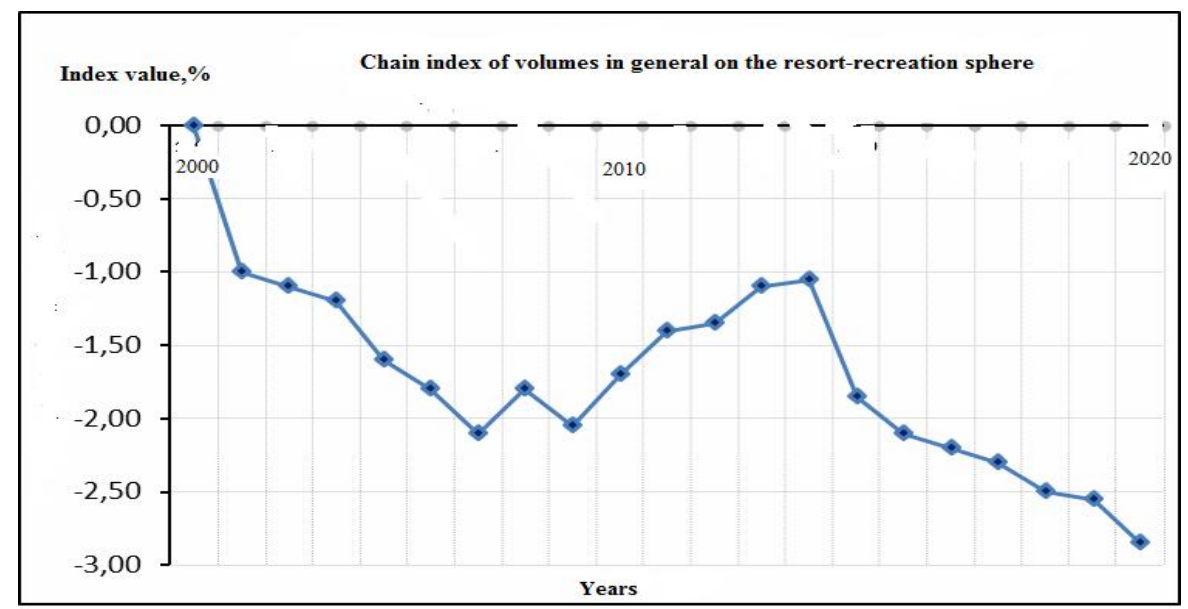

Fig. 1. The chain index of volumes in general on the resort-recreation sphere and its trend for the period $T_{1}=2000-T_{2}=2020$ years

The great depth of the transformation crisis in the resort-recreation economy reflects the great complexity of the pre-national complex. This process causes the higher the level of development of such systems, the earlier the deeper the transformational crisis in them. This is one of the differences of economic transformation in Ukraine from other countries. Another reason for this is that there are significant disparities in the national economy, when the resort-recreation sector has not been given due attention. At the same time, in developed market economies, resorts and tourism are among the main budget-forming industries. Another cause of the crisis is the sharp decline in demand for national resort-recreation products. It is caused by low consumer solvency, quality of services provided, low competitiveness of Ukrainian health resorts and unpromising development strategy.

Against the background of the general trend of the transformation crisis, small cycles of the dynamics of production of resort-recreation products are observed. 
Thanks to these cycles, the crisis develops rather unevenly, with shocks (Fig. 1), periods of its sharp acceleration, alternating periods of short-term stabilization and recovery. Such cycles are not typical of sustainable economies. Therefore, the national resort-recreation economy can be characterized as a fast-changing economy, and this significantly differentiates it from existing stable economies. Thus, there is another strategic systemic effect.

The way out of this situation is the transition to a new strategy for the development of the resort-recreation sector, which involves the predominant provision of resort-recreation services integrated with the leisure and tourism industries. Such a transition is always accompanied by economic transformations associated with the transformation of the existing structure of the resort-recreation systems, and structural changes in the economy. In Fig. 2 shows a chart of the chain index of structural shifts in the production of resort-recreation products $d_{t}$, which shows how quickly structural changes occur in this case. From the graphics it follows that the intensification of changes in the volume of production of resort-recreation products in the transition to a new strategy for the development of resort-recreation sphere is accompanied by intensification of changes in the structure of systems. Such dynamics confirms the hypothesis that there is an effect of linking the intensity of structural shifts with the rate of change in the volume of production of resort-recreation products.

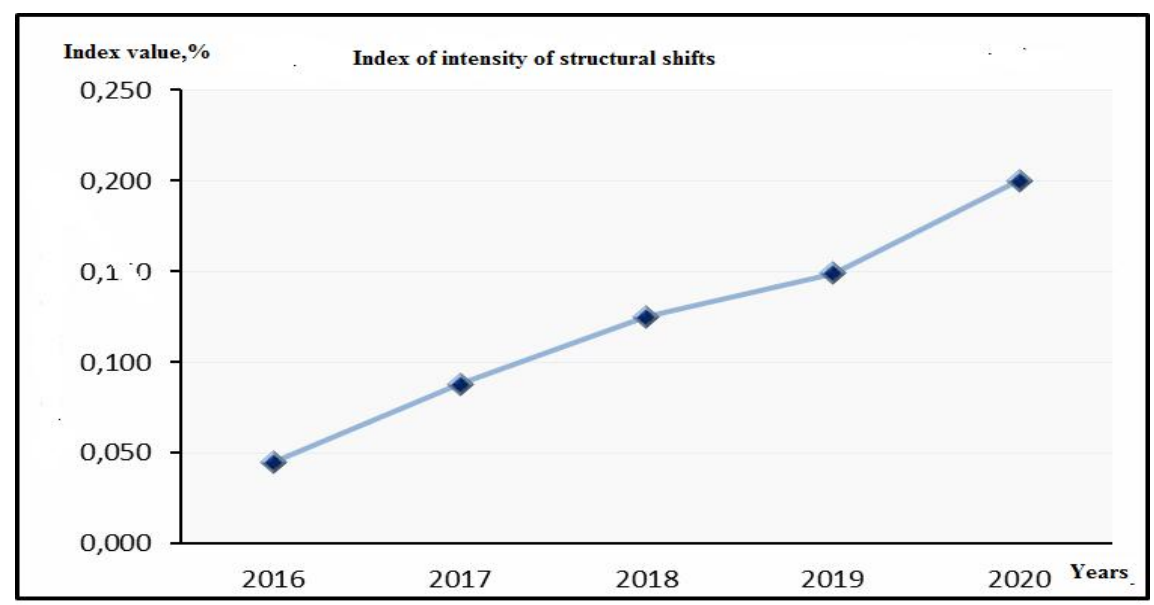

Fig. 2. Index of intensity of structural shifts $d_{t}$

As the indicator of forward structural shifts, we will use the basic index of structural shifts $D_{t_{1}, t_{2}}$ (fig. 3). Calculation results, which are presented in fig. 3 show that in case of transition to the new development strategy for the analyzed period in the resort-recreation sphere there will be considerable shifts in structure of production of resort-recreation products. 


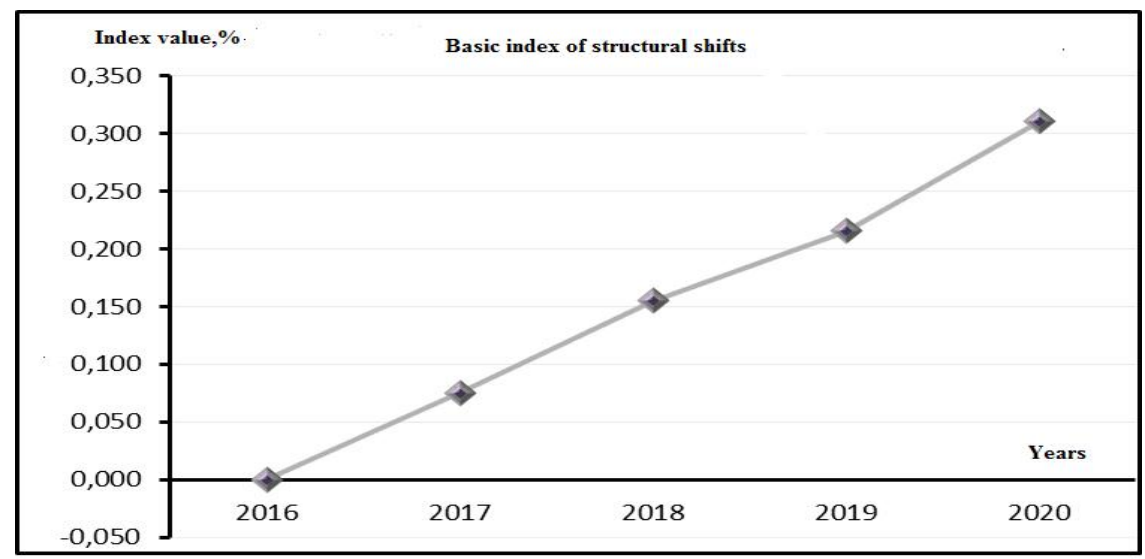

Fig. 3. Basic index of structural shifts $D_{t_{1}, t_{2}}$

In particular, the tendency to withdrawal of proportions of production from proportions, existing prior to economic transformations is observed. Value $D_{t_{1}, t_{2}}$ shows the considerable scale of such removal for all analyzed period. That circumstance that $D_{t_{1}, t_{2}}$ grows with growth $\left|t_{2}-t_{1}\right|$ indicates existence of forward structural shifts on all considered time interval.

For the analysis of orientation of structural shifts, we will make calculations and we will construct the schedule of the index of quality of structure of production of resort-recreation products $G_{t}$ (fig. 4). Dynamics $G_{t}$ shows steady growth throughout the analyzed period. Therefore, upon transition to the new development strategy, the quality of structure of a system improves, and production of innovative resortrecreation products grows at the advancing rates.

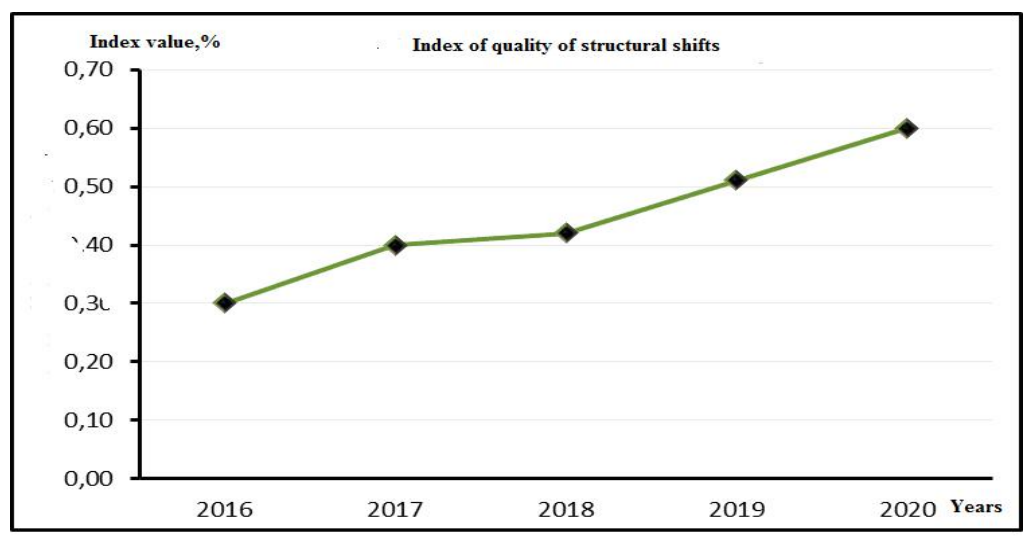

Fig. 4. Index of quality of structural shifts $G_{t}$

Thus, the index of quality validates the choice of the direction of carrying out transformations. That is transformational process in the resort-recreation sphere has to be followed by structural shifts of such orientation and can be considered as one more strategic system effect. 
Conclusion. The carried-out analysis shows that one of results of strategic economic transformations in resort-recreation economy is transition to the new development strategy that is transition from the market of the seller to the market of the buyer. At the same time change of the principles of functioning of resort and recreational systems is observed. It, in turn, generates numerous strategic system effects to which number, it is necessary to refer structural shifts. Also numerous more local effects which, finally, lead to increase in efficiency of resort-recreation and tourist systems are observed.

\section{REFERENCES}

1. Barro, R. J. (2016). Economic Growth in a Cross Section of Countries. The Quarterly Journal of Economics, 106(2), 407-443.

2. Brownrigg, M. (2017). Differential multipliers for tourism. Scottish Journal of Political Economy, 1(3), 29-37.

3. Campbell, A. (2018). Strategic synergy. Washington: An International Thomson Publishing Company.

4. Flaschel, P. (2017). Dynamic Macroeconomics. Instability, Fluctuation, and Growth in Monetary Economics. Cambridge: The MIT Press.

5. Humeniuk, V. (2019). Financial security of enterprises in resort and recreation sphere. Financial and credit activity: problems of theory and practice, 1(28), 87-94. Available at: https://doi.org/10.18371/fcaptp.v1i28.164013

6. Humeniuk, V. (2018). Financial nature of resort multiplier. Financial and credit activity: problems of theory and practice, 2(25), 417-423. Available at: https://doi.org/10.18371/fcaptp.v2i25.136501

7. Ravenscroft, N. (2019). Recreation Planning \& Development. N.Y.: McMillan.

8. The State Statistics Service of Ukraine. (2018). Materials of economic activity Available at: http://www.ukrstat.gov.ua/ [in Ukrainian].

9. William, A. (2017). Recreation and the Local Economy an Input-Output Model of a Recreation-Oriented Economy. Graduate School of Business University of Wisconsin-Madison. 